\title{
TEMPORARY REMOVAL: Is noise reactivity reflected in auditory response variables, including those that measure cognition, in dogs? Initial findings
}

\author{
Peter M. Scheifele ${ }^{1}$, Kristine E. Sonstrom ${ }^{2}$, Arthur E. Dunham ${ }^{3}$, Karen L. Overall ${ }^{3}$ \\ ${ }^{1}$ University of Cincinnati, 3202 Eden Ave., Cincinnati, Ohio USA 45267 \\ ${ }^{2}$ The University of Akron, The Polsky Building 181, 225 S. Main Street, Akron, OH USA 44325-3001 \\ ${ }^{3}$ University of Pennsylvania, 206 Goddard Lab, 233 S. University Ave. Philadelphia, PA USA 19104-6018
}

The publisher regrets that this article has been temporarily removed. A replacement will appear as soon as possible in which the reason for the removal of the article will be specified, or the article will be reinstated.

The full Elsevier Policy on Article Withdrawal can be found at http://www.elsevier.com/locate/ withdrawalpolicy. 